\title{
BIODIVERSITY IN INDIA: CHALLENGES AND OPPORTUNITIES
}

\section{Purnima Gaur and Tuhina Johari}

Dept. of Political Science, Government Nehru Arts College, Agar Malwa, M.P. Corresponding author Email : purnimaranigaur@gmail.com

\begin{abstract}
:
Biodiversity in India: Challenges and Opportunities Dr. Purnima Gaur* Dr. Tuhina Johri* *Department of Political Science, Government Nehru Arts College, Agar Malwa, Madhya Pradesh *Department of Political Science, St. Aloysius College (Autonomous), Jabalpur, Madhya Pradesh Biodiversity is currently the buzzword of the day. It is fundamental to the existence of life on the earth and provides the base for the livelihoods, cultures and economies of several hundred millions of people, including farmers, fisher folk, forest dwellers and artisans. It contributes to many aspects of people"s livelihoods and well-being, providing products, such as food and fibers, whose values are widely recognized. Biodiversity is a wealth to which no value can be put. It boosts ecosystem productivity where each species, no matter how small, all have an important role to play, so, while we dominate this planet, we still need to preserve the diversity in wildlife. Biodiversity is nature"s greatest gift to humanity. Humans are part of this biodiversity too with the potential to protect or destroy it. India"s constitution explicitly guide government under Art.48A of its Directive Principle of State Policy and its citizen under fundamental duty Art.51Ag to protect wildlife, forest and environment of country.
\end{abstract}

\section{Keywords:}

Biodiversity and indian act

\section{Introduction:}

Biodiversity is currently the buzzword of the day. It is fundamental to the existence of life on the earth and provides the base for the livelihoods, cultures and economies of several hundred millions of people, including farmers, fisher folk, forest dwellers and artisans. It contributes to many aspects of people"s livelihoods and well-being, providing products, such as food and fibers, whose values are widely recognized. Biodiversity is a wealth to which no value can be put. It boosts ecosystem productivity where each species, no matter how small, all have an important role to play, so, while we dominate this planet, we still need to preserve the diversity in wildlife. Biodiversity is nature"s greatest gift to humanity. Humans are part of this biodiversity too with the potential to protect 
or destroy it. Currently, our activities are destroying the biodiversity structure at alarming rates. Increasing population and changing lifestyle leads to extensive commercial exploitation of the natural resources. Human activity has always had an impact on biodiversity, Losses of biodiversity have resulted from the destruction of natural habitats, over-exploitation of resources, pollution and changes in the composition of ecosystems. The loss of biodiversity affects not only the physical environment but also the social, cultural, religious and spiritual well being of human life. Loss of biodiversity is our loss. Today, loss of biodiversity through disappearing sacred natural sites has become a global concern. Globally, humans are now the dominant influence on biodiversity. Loss of biodiversity may trigger large unpredictable changes in an ecosystem and some of these may adversely impact agriculture or human health. In recent times, biodiversity has become easy targets for human over-exploitation due to burgeoning human populations and the quest for a "better life" through improvements in science and technology. Biodiversity, therefore, is being exploited at much faster rates than ever before with negative implications for sustainable human livelihood (Turner et al., 1990).

\section{Material and Method:}

Threats of Biodiversity

\section{Result and Discussion:}

The conservation, protection and management of Biodiversity got a boost after the Rio summit of 1992 where the foundation of UN Conservation of Biodiversity was established. National Biodiversity Act 2002 was adopted to realize the objective of UN"s CBD 1992. The act aims to conserve, protect and preserve biodiversity, sustainable use of the components of biological diversity, fair and equitable sharing of benefits arising out of utilization of genetic resources. It laid the way to the establishment of a number of National Parks, Wildlife sanctuaries, Marine Hotspots and biosphere reserves. 


\section{Conclusion:}

Shaping the future of our country and the world towards sustainable development requires a continuous monitoring of our biodiversity and then inclusive growth can be achieved. Every individual can make a small and yet significant effort in the race to save our planet and conserve biodiversity. More policy tools and mechanisms based on success should develop, new ways will emerge to conserve and use the world"s biodiversity. Business activity should be environmental friendly and successful more than only making a profit. It must be ecologically acceptable, socially beneficial and economically profitable. Make children aware of their surroundings and the need for biodiversity.

Promote bio-farming which is less intensive and environmental-friendly. Make use of sustainable technologies like smokeless chulhas, ground water recharging unit, wind energy, solar power, etc. 